\title{
Wer schneller geht, ist früher draußen
}

— Wie gut ein alter Mensch noch zu Fuß ist, verrät viel über seine gesundheitliche Prognose - auch dann, wenn er in ein Krankenhaus eingewiesen wird.

Dass das Gehtempo alter Menschen Rückschlüsse auf ihre Prognose erlaubt, ist mehrfach gezeigt worden. Viele Studien beschränkten sich allerdings auf medizinisch stabile Senioren. Eine neue Studie belegt jetzt, dass ein Gehtest auch bei akut kranken Personen sicher ist und wichtige Informationen über die Prognose liefern kann. Die Patienten waren wegen einer kardiovaskulären, respiratorischen oder gastroenterologischen Erkrankung in eine geriatrische Akutklinik eingewiesen worden. In- nerhalb von 24 Stunden nach der Aufnahme wurden sie gebeten, einen Gehtest zu absolvieren, bei dem sie aus dem Stand heraus 2,4 Meter zurücklegen sollten. Die insgesamt 322 Patienten (65-85 Jahre) hatten meistens mehrere Begleiterkrankungen, aber keine Zeichen einer Demenz.

Nur knapp zwei Drittel der Patienten schafften den kurzen Weg, mit einer mittleren Geschwindigkeit von 0,53 m/s. Auch wenn Alter, Geschlecht und Alltagskompetenz berücksichtigt wurden, korrelierte ihr Tempo mit der Dauer ihres Krankenhausaufenthaltes. Patienten, die die Strecke nicht bzw. mit weniger als $0,4 \mathrm{~m} / \mathrm{s}$ schafften, wurden erst 1,9 bzw. 1,4 Tage später entlassen als Patienten mit einem Tempo von mindestens $0,6 \mathrm{~m} / \mathrm{s}$. Sie hatten im Vergleich zu den mobileren Patienten auch schlechtere Chancen, nach der Entlassung in ihr Zuhause zurückzukehren. In beiden Punkten war der Gehtest aussagekräftiger als die von den Patienten berichteten Einschränkungen bei den Alltagsaktivitäten. Die Autoren um Glenn V. Ostir, Galveston/ Texas, schlagen vor, bei Klinikaufnahme geriatrischer Patienten auch einen Gehtest durchzuführen. Eine Geschwindigkeit unter $0,4 \mathrm{~m} / \mathrm{s}$ sei ein Indikator "für einen schlechteren funktionellen Zustand und eine langsamere Regeneration des Patienten". BS Ostir GV et al. Arch Intern Med 2012;172(4):353-358

\section{Märchenstunde mit Mumie}

Es war einmal vor langer Zeit ein uriger Tiroler. Der ernährte sich von Vollkorngetreide aus ökologischem Landbau und stieg rüstig den Berggipfeln zu. Die Forscher, die ihn nach 5300 Jahren aus dem Gletschereis im Ötztal bargen und auf den Namen Ötzi tauften, soll er dem Vernehmen nach mit einem tirolerischen „Heil am Seil!" begrüßt haben. Die Wissenschaftler freuten sich, auf einen Menschen zu treffen, der immer genauso gelebt hatte, wie es die Medizin verlangt: Er hatte weder Tabak noch Alkohol bei sich, aß ballaststoffreich und bewegte sich viel an der frischen Luft. Noch mehr freuten sie sich auf seine mutmaßlich traumhaften Lipidwerte und die Röntgenaufnahmen seiner jungfräulichen Arterien, mit deren Hilfe sie den Nutzen leitliniengerechter Lebensweise ein für allemal nachweisen wollten.

Doch daraus wird wohl nichts. Denn glaubt man den Analysen einer internationalen Forschergruppe um die Paläogenetiker der Europäischen Akademie Bozen (Nature Communications 2012; DOI: $10.1038 /$ ncomms1701), ist die Ge- schichte vom plaquefreien Körnerguru aus dem Eis ein präventionsmedizinisches Märchen. Und das nicht nur deshalb, weil der Ötzi schon zu Steinzeiten, im Alter von nur 45 Jahren, von einem Bogenschützen gemeuchelt worden war.

Vielmehr entpuppt sich die vermeintlich vor $\mathrm{Ge}$ sundheit strotzende Mu-

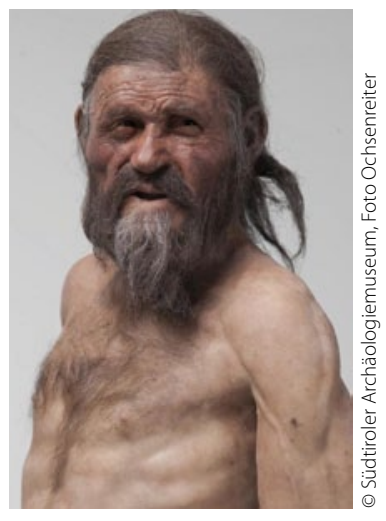

Sieht so ein gesunder 45-Jähriger aus? Der Ötzi, rekonstruiert. und ein Feuerstein? Ist der Eismann gar ein kühler Blender, ein Steinzeitwulff, der nur deshalb trotz Lyme-Arthritis auf Wanderurlaub ging, weil Freunde dafür aufkamen?

Die Antworten stehen in Ötzis Genom geschrieben. Die Forscher aus Bozen haben darin gelesen und berichten, Gefäßsklerose und Hypermie aus Südtirol in der Synopsis als frühzeitlicher Herzkasper, dessen Leben auch ohne Mordanschlag an einem Fädchen hing - von wegen „Heil am Seil“. Im Blut zu viel Fett, rieselnder Kalk in den Adern: Wie es aussieht, kam der tödliche Pfeil dem Infarkt nur wenig zuvor. Obendrein entdeckten die Bozener Wissenschaftler die Spuren einer Borrelieninfektion in Ötzis Knochen. Das wirft Fragen auf. Hat der Ötzi vielleicht Vollkorn gepredigt und selbst Ötztaler Speck in sich hineingestopft? Hat er heimlich geraucht - in seiner Tasche befanden sich immerhin Zunder cholesterinämie seien der späteren $\mathrm{Mu}$ mie schon in die steinerne Wiege gelegt worden. Das Erbe wuchs sich gewissermaßen zu einem prähistorisch-metabolischen Syndrom aus, dem allein mit vollem Korn, Rauchverzicht und Bergsport nicht beizukommen war. Die Gene übrigens, speziell die Haplogruppe G2a4, stammen vermutlich aus dem Nahen Osten und geistern heute noch auf Sardinien und Korsika umher. Ötzi ist demnach zwar kein Blender. Aber ein waschechter Tiroler ist er auch nicht.

DR. ROBERT BUBLAK 